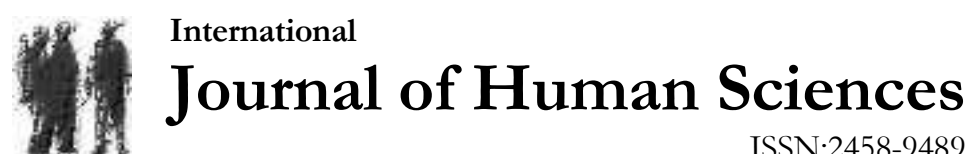

Volume: 18 Issue: 4 Year: 2021

\section{A study on mushroom management perception of employees in \\ Provincial Directorates of Youth and Sports (Niğde province example)}

\section{Gençlik ve Spor İl Müdürlüklerinde çalışanların mantar yönetim algısı üzerine bir çalışma (Niğde ili örneği)}

\author{
Fatih Dinç ${ }^{1}$ \\ Ahmet Erdi Avanoğlu²
}

\begin{abstract}
It seems that the mushroom management metaphor has become a new research area in management sciences. This management style takes its name from mushroom cultivation in terms of method similarity. In mushroom cultivation; mushrooms are left in the dark and only allowed to grow by giving them the resources they need. In the mushroom management metaphor, managers leave employees in a kind of darkness. They provide only the resources they need without conducting mutual communication with them and does not need to share information with the employees. At the end of this process, managers expect an increase in performance from their employees. Within the scope of this study, it was aimed to measure the mushroom management perceptions of 4-a and 4-b employees in Niğde Provincial Directorate of Youth and Sports. The sample of the study consists of 92 civil servants, 42 women and 50 men, working in the Niğde Provincial Directorate of Youth and Sports. Personal information form and the "Mushroom Management Scale" developed by Birioğlu and Tekin (2018) were used as data collection tools. Descriptive statistics were used
\end{abstract}

Özet

Mantar yönetim metaforunun, yönetim bilimlerinde yeni bir araştırma alanı haline geldiği görülmektedir. Bu yönetim tarzı ismini metot benzerliği açısından mantar yetiştiriciliğinden almaktadır. Mantar yetiştiriciliğinde; mantarlar karanlıkta bırakılır ve sadece ihtiyacı olan kaynaklar verilerek yetişmesi sağlanır. Mantar yönetim metaforunda da yöneticiler, çalışanları bir çeşit karanlıkta bırakır; onlarla karşıllklı iletişim yürütmeden sadece onların ihtiyacı olan kaynakları sağlar ve çalışanlarla bilgi paylaşımına gerek duymaz. Bu sürecin sonunda yöneticiler, çalışanlardan performans artış1 beklerler. $\mathrm{Bu}$ çalışma kapsaminda, Niğde Gençlik ve Spor il Müdürlüğünde 4-a ve 4-b çalışan personellerin mantar yönetim algılarının ölçülmesi amaçlamıştır. Çalışmanın örneklemini, Niğde Gençlik ve Spor İl Müdürlügünde çalışan, 42 kadın, 50 erkek olmak üzere toplam 92 memur oluşturmaktadır. Veri toplama aracı olarak kişisel bilgi formu ve Birincioğlu ve Tekin (2018) tarafindan geliştirilen "Mantar Yönetim Ölçeği”" kullanılmıştır. Verilerin analizinde tanımlayıc1 istatistikler, ikili karşılaşturmalarda T-testi, ikiden fazla karşılaştırmalarda Anova testi

Dr. Ögr. Üyesi, Niğde Ömer Halisdemir Üniversitesi, Spor Bilimleri Fakültesi, fatihdinc33@gmail.com D) Orcid ID: https://orcid.org/0000-0001-6022-977X

3 Arş. Gör., Niğde Ömer Halisdemir Üniversitesi, Spor Bilimleri Fakültesi, e.avanoglu@gmail.com (iD) Orcid ID: https://orcid.org/0000-0001-6022-977X 
Dinç, F., \& Avanoğlu, A. E. (2021). Gençlik ve Spor İl Müdürlüklerinde çalısanların mantar yönetim algisı üzerine bir çalışma (Niğde ili örneği). Journal of Human Sciences, 18(4), 772-781. doi:10.14687/jhs.v18i4.6249

in the analysis of the data, T-test was used for pairwise comparisons, and ANOVA test was used for more than two comparisons. As a result, according to the findings, it was determined that the employees had a medium level of mushroom management perception. No significant difference was found between the sub-dimensions of administrative duty, gender, age, and tenure.

Keywords: Mushroom management, sports management, sports organization, sport.

(Extended English summary is at the end of this document) uygulanmiştır. Sonuç olarak; elde edilen bulgulara göre çalsşanların orta düzeyde mantar yönetim algisına sahip oldukları belirlenmiştir. İdari görev, cinsiyet, yaş ve görev süresi ile alt boyutlar arasında hiçbir anlamlı farklılık tespit edilememiştir.

Anahtar Kelimeler: Mantar yönetim, spor yönetimi, spor örgütü, spor.

\section{Giriş}

Sosyal bir varlık olan insan, var olduğun günden bu güne yaşamını sürdürebilmek amacıyla sürekli bir arayışa girmektedir. Bununla beraber yaşam kalitesini arttırmak için yenilik arayışı içindedir. Bu bağlamda bireyler, zaman içerisinde topluluklar oluşturarak, ortak ihtiyaçlarının belirlenmesi ve giderilmesi amacıyla bir araya gelmektedirler. Bu doğrultuda, insanların hem yönetme hem de yönetilmesi ihtiyacı doğmaktadır (Turan ve Güler, 2018). Yönetim, insan ve diğer örgütsel kaynakları (iş gücü, sermaye, teknik donanım vb.) organize eder. Bununla birlikte, örgütsel amaçlara ulaşmak ve örgütü geliştirmek için bütün maddi ve manevi unsurların bir araya toplanmasıyla yönetim, planlama, örgütleme, koordinasyon, yöneltme ve denetleme gibi fonksiyonların uygulanmasıdır. Yönetim, günümüz dünyasında örgütlerde performansın sürdürülebilir olmasının temeli olarak görülmektedir. Örgütü oluşturan bireylerin kurallara ve yönetmeliklere uymaları halinde amaçlarına hızlı, etkili ve verimli bir şekilde ulaşacakları söylenebilir (Yetim, 2019, s.5-6).

Günümüzde işletmeler etkinliklerini arıtmak için değişen ve gelişen piyasa koşullarına uyum sağlamada yeni yönetim anlayışları benimsemişlerdir. İşletmeler ya da kurumlar hızla artan ve çeşitlenen piyasa koşullarına ayak uydurmak amacıyla, iş gücü yönetiminin etkili ve koordineli bir biçimde uygulanmasının gerekliliği ortaya çıkmaktadır (Korkut ve ark., 2015). Son yıllarda yeni bir yönetim anlayışı olarak mantar yönetim modeli ilgili alan yazınında karşımıza çıkmaktadır. Ancak bu konunun literatürü sınırlıdır. Mantar yönetim metaforu, çalışanlara kurumları ve görevleri hakkında sınırlı bilgi verilmesidir (Herman, 1997, 66). Mantar yönetim anlayışı, mantar yetiştiriciliğinden esinlenerek bir metafor olarak ortaya çıkmıştır. Mantar yetiştiriciliğinde, mantarlar karanlıkta bırakılarak onlara gereği kadar gübre ve su verilmektedir. Bu metafor anlayışında yöneticiler, mantar yetiştiriciliğinde olduğu gibi çalışanları adeta karanlıkta bırakarak onlardan maksimum performans beklemektedir. Yüksek fayda bekleyen yöneticiler, çalışanlara sadece ihtiyaçları olan bilgi ve kaynakları vererek karanlıkta bırakmış olurlar (Birincioğlu ve Tekin, 2018, 170; Kıllı̧, 2015). Bu tutumdaki yöneticiler, sahip oldukları bilgi ve gücü çalışanları ile paylaşmazlar. Bunula birlikte işleri, astlarına gerektiğini düşündükleri kadar bilgileri vererek yaptırırlar (Mar, 2011). Çalışanların, gerekenden daha fazla bilgiye ulaşmaları, kendilerini ifade etmeleri ve alınan kararlara katılmaları mantar yönetim anlayışı açısından istenmemektedir. Bu yönetim anlayışında liderler kendi başlarına karar alma eğilimindedir. Bundan dolayı demokratik bir teşkilatlanmadan bahsedilemez (Mar. 2011, Kıllı̧ ve Olgun 2017). Bu açıdan bakıldığında otokratik lider özellikleri ortaya koyan yöneticilerin mantar yönetim anlayışıyla örtüşen bir tavır sergiledikleri söylenebilir. Otokratik liderler, yetki plan ve kararları elinde bulundurur ve astlarına söz hakkı tanımazlar (Altan ve Özpehlivan, 2019). 
Dinç, F., \& Avanoğlu, A. E. (2021). Gençlik ve Spor İl Müdürlüklerinde çalıșanların mantar yönetim algısı üzerine bir çalışma (Niğde ili örneği). Journal of Human Sciences, 18(4), 772-781. doi:10.14687/jhs.v18i4.6249

Smith (2002)'e göre mantar yönetim uygulanan örgütlerde bilgi akışı yetersiz insanlar, hızlı değerlendirme ve karar vermek zorunda olduklarında nasıl davranacaklarını bilemezler. Yöneticinin, çalışanların işlerini tamamlamalarında gerekli olan bilginin önüne geçmesi, çalışanların karanlıkta bırakılmasına ve iletişimde tek yönlülüğe veya bilgi asimetrisine neden olabilir (Kılıç ve Olgun, 2017; Kahya ve Ceylan, 2019). Geckoboard ve Censuswide (2015) çalışmalarında mantar yönetimin hakim olduğu işletmelerde, çalışanlar ile yetersiz bilgi paylaşımında bulunması kurum performansını olumsuz yönde etkileyeceği ancak yeterli bilgi paylaşımında bulanmaları halinde şirket performansının artacağını belirlemişlerdir. Bu noktada işletmeler, yüksek veya düşük erişimli olarak ikiye ayrılabilir. Yüksek erişimli işletmelerde aktif bir bilgi paylaşımı görülürken düşük erişimli işletmelerde ise yetersiz seviyede bilgi paylaşımı görülmektedir. Bu bağlamda, bilgi akışı yetersiz işletmelerin yönetim modeli olarak mantar yetiştiriciliğine benzer bir yapı da olduğu söylenebilir (Çetin, 2021). Gunn (1995)'e göre mantar yönetim tarzını benimseyen yöneticiler çalışanları karar alma sürecine dâhil etmezler. Bunun nedeni; yanlış uygulamaların üzerini örtmek, eleştiriye maruz kalmamak ve sorgulanmamaktır. Baxter (2005)'e göre mantar yönetimde geri bildirim yok denebilecek seviyede ve belirsizlik yüksektir. Ancak bu yönetim şekli olumsuz gibi görünse de farklı açılardan bazı faydalar sunmaktadır. Örneğin, mantar yetiştiriciliğinde olduğu gibi kör bırakılan çalışanların, neredeyse çok sınırlı sorumluluğa sahip olması nedeniyle, vermeleri gereken kararların miktarı oldukça azdır. Bu durum ise iş yerindeki stresi azalıı (Neill \& Laplante, 2005). Kılıç’a (2015) göre; gizliliğin ihlal edilmesinin önüne geçmek, prosedürler, çalışanlar arası çatısmaları önlemek, panik ve kaosu önlemek, örgütün saygınlığını korumak, düzeni sağlamak ve örgüt içerisinde meydana gelecek söylentilerin önüne geçmek amacıyla, mantar yönetim uygulanmaktadır. Smart (2012)'a göre, Titanik gemisinin buz dağına çarpmak üzere olduğunun çok az kişiye bildirilmesinin nedeni, yolcularda panik oluşmasının engellenmesidir. Bu yönüyle mantar yönetim eğiliminde olan yöneticilerin, birtakım bilgileri çalışanlardan gizleyerek örgütün daha iyi yönetileceği düşüncesine sahip oldukları söylenebilir.

Mantar yönetim anlayışının birçok örgütte olduğu gibi spor örgütlerinde de olumlu ve olumsuz sonuçları olabilir. Bu bilgiler doğrultusunda bu çalışmada, Niğde Gençlik ve Spor İl Müdürlüğü'nde çalışan personelin mantar yönetim algısının incelemesi amaçlamıştır. Elde edilecek bulgular 1şığında alana katkı sağlaması açısından önemli olduğu düşünülmektedir. Dahası kurumsal açıdan öneriler getirilebilir.

\section{Materyal ve Metot}

Bu çalışma betimsel ve nicel bir çalışma olup betimsel tarama modelindedir. Aşağıda araştırma sorularına cevap aranmıştır;

- Çalışanların mantar yönetim algısı yaşa göre farklılaşmakta mıdır?

- Çalışanların mantar yönetim algısı cinsiyete göre farklılaşmakta mıdır?

- Çalışanların mantar yönetim algisı görev süresine göre farklılaşmakta mıdır?

- Çalışanların mantar yönetim algısı devam idari göreve göre farklılaşmakta mıdır?

Çalışmada katılımcılardan bilgilendirilmiş gönüllü onam formu alınmış olup, Niğde Ömer Halisdemir Üniversitesi etik kurulu tarafindan etik yönden incelenmiş olup 01/04/2020 tarih ve 03 sayll toplantısında, oybirliği ile etik açıdan uygun olduğuna karar verilmiştir.

\subsection{Evren ve Örneklem}

Araştırmada 2021 yllında Niğde Gençlik ve Spor İl ve İlçe Müdürlüklerinde 4a ve 4b statüsünde çalışan toplamda 185 personelden pandemi nedeniyle 90 kişiye ulaşılabilmiştir. Araştırmada personelin, mantar yönetim algısını ölçmek için tesadüfi olmayan örnekleme yöntemi kullanılmıştır.

\subsection{Veri Toplama Teknikleri}

Araştırmada veri toplama aracı olarak kişisel bilgi formu ve Birincioğlu ve Tekin (2018) tarafından geliştirilen "Mantar Yönetim Ölçeği” kullanılmıştır. Ölçekte yer alan maddelerle ilgili mantar yönetimi ifade etmek için 5'li Likert tipi dereceleme kullanılmıştır. Ölçek 19 maddeden ve 
Dinç, F., \& Avanoğlu, A. E. (2021). Gençlik ve Spor İl Müdürlüklerinde çalıșanların mantar yönetim algısı üzerine bir çalışma (Niğde ili örneği). Journal of Human Sciences, 18(4), 772-781. doi:10.14687/jhs.v18i4.6249

dört faktörlü bir yapıdan oluşmaktadır. Bu faktörler Yetersiz Bilgi Paylaşımı (1, 2, 3, 4, 5, 6), Güç Kaybı Endişesi (7, 8, 9, 10, 11), İletişim Yetersizliği (12, 13, 14, 15) ve Katılım Yönetim Eksiği(16, 17, 18, 19) olarak adlandırılmıştır. Ölçeğin iç tutarlık güvenirliği için Cronbach alfa katsayısı hesaplanmış ve 19 maddelik ölçeğin iç tutarlık katsayısı 0.90 olarak hesaplanmıştır. Ölçeğin alt faktörlerine ilişkin iç tutarlık katsayıları ise, yetersiz bilgi paylaşımı için 0.89; güç kaybı endişesi için 0.87; iletişim yetersizliği için 0.81 ve profesyonel yönetim eksikliği için ise, 0.83 olarak belirlenmiştir (Birincioğlu ve Tekin, 2018). Bu bilgilerin 1şığında çalışmada iç tutarlık katsayısı 0.73 olarak hesaplanmıştır.

\subsection{Verilerin Analizi}

Verilerin analizinde tanımlayıcı istatistikler, verilerin normal dağılım gösterip göstermediği Kolmogorow Smirnov testi ile incelenmiş olup, sonuçların -1 ve +1 arasında olduğu görülmüsstür. Bu bağlamda, parametrik testlerden ikili karşılaştırmalarda T-testi, ikiden fazla karşılaştırmalarda Anova testleri kullanılmıştır.

\section{Bulgular}

Çalışmanın bu bölümünde katılımcıların Mantar Yönetim Ölçeği’ne dair verdikleri cevaplardan elde edilen verilere göre istatiksel analizlerin sonuçlarına yer verilecektir.

Tablo 1. Katılımcılara Ait Demografik Bilgiler

\begin{tabular}{|c|c|c|c|c|}
\hline Değişkenler & & $\mathbf{N}$ & $f$ & $\%$ \\
\hline \multirow{2}{*}{ Cinsiyet } & Erkek & 50 & 50 & 54,3 \\
\hline & Kadın & 42 & 42 & 45,7 \\
\hline \multirow{5}{*}{ Yaş } & 24-29 yaș arası & 15 & 15 & 16,3 \\
\hline & $30-35$ yaş aras 1 & 34 & 34 & 37,0 \\
\hline & 36-41 yaş aras1 & 13 & 13 & 14,1 \\
\hline & $42-47$ yaş aras1 & 6 & 6 & 6,5 \\
\hline & 48 yaş ve üzeri & 24 & 24 & 26,1 \\
\hline \multirow{2}{*}{$\begin{array}{l}\text { Devam Eden } \\
\text { İdari Görev }\end{array}$} & Evet & 32 & 32 & 34,8 \\
\hline & Hayır & 60 & 60 & 65,2 \\
\hline \multirow{4}{*}{$\begin{array}{l}\text { Eğitim } \\
\text { Seviyesi }\end{array}$} & Lise & 13 & 13 & 14,1 \\
\hline & Ön lisans & 7 & 7 & 7,6 \\
\hline & Lisans & 52 & 52 & 56,5 \\
\hline & Lisansüstü & 20 & 20 & 21,7 \\
\hline \multirow{5}{*}{ Görev Süresi } & 1-3 Yil & 15 & 15 & 16,3 \\
\hline & 4-6 Yil & 38 & 38 & 57,6 \\
\hline & 7-9 Y1l & 9 & 9 & 9,8 \\
\hline & 9 ve yll ve üzeri & 30 & 30 & 21,7 \\
\hline & Toplam & 92 & 92 & 100 \\
\hline
\end{tabular}

Tablo 1'de katulımcılara ait demografik bilgilere yer verilmiştir. Tabloya göre; katılımcıların \% 54,3’ü erkek, \% 37’si 30-25 yaş aralı̆̆ında, \% 65,2'sinin idari görevi bulunmamakta, \% 56,5’i lisans mezunun, \% 57,6’s1 4-6 yıl süre ile çalıştı̆ı görülmektedir

Tablo 2. Katılımcıların Mantar Yönetime İlişkin Tanımlayıcı İstatistikleri

\begin{tabular}{lccccc}
\hline & N & $\mathbf{x}$ & Ss & Min. & Max. \\
\hline Yetersiz Bilgi Paylaşımı & 92 & 18,85 & 3,65 & 9 & 27 \\
\hline Güç Kaybı Endişesi & 92 & 14,38 & 2,90 & 5 & 23 \\
\hline Yetersiz İletişim & 92 & 13,18 & 2,16 & 9 & 19 \\
\hline Katılımc1 Yönetim Eksikliği & 92 & 10,73 & 4,50 & 4 & 20 \\
\hline Toplam puan & 92 & 57,14 & 10,06 & 43 & 82 \\
\hline p $<0,05$ & & & & &
\end{tabular}


Dinç, F., \& Avanoğlu, A. E. (2021). Gençlik ve Spor İl Müdürlüklerinde çalıșanların mantar yönetim algısı üzerine bir çalışma (Niğde ili örneği). Journal of Human Sciences, 18(4), 772-781. doi:10.14687/jhs.v18i4.6249

Tablo 2'de mantar yönetime ilişkin istatiksel analizlerine yer verilmiştir. Mantar yönetim ölçeğin alınabilecek en az puan 9 en yüksek puan 95 olduğuna göre katılımcılarım aldıkları 57,14 puana göre orta düzeyde mantar yönetime maruz kaldıkları tespit edilmiştir. Bununla birlikte çalısanların mantar yönetim alg1sı alt boyutlara göre orta seviyede olduğu tespit edilmiştir.

Tablo 3. Cinsiyet Değişkeni Üzerinden Alt Boyutların Karşılaştırldığı T-Testi

\begin{tabular}{|c|c|c|c|c|c|c|c|}
\hline Ölçek ve Alt Boyutları & Grup & $\mathbf{N}$ & $\mathbf{x}$ & Ss & sd & $T$ & $\mathbf{P}$ \\
\hline \multirow{2}{*}{ Yetersiz Bilgi Paylaşımı } & Erkek & 50 & 18,60 & 3,95 & \multirow{2}{*}{90} & \multirow{2}{*}{$-0,709$} & \multirow{2}{*}{0,48} \\
\hline & Kadin & 42 & 19,14 & 3,27 & & & \\
\hline \multirow{2}{*}{ Güç Kaybı Endişesi } & Erkek & 50 & 14,54 & 2,92 & \multirow{2}{*}{91} & \multirow{2}{*}{0,573} & \multirow{2}{*}{0,568} \\
\hline & Kadın & 42 & 14,19 & 2,92 & & & \\
\hline \multirow{2}{*}{ Yetersiz İletişim } & Erkek & 50 & 12,96 & 2,14 & \multirow{2}{*}{92} & \multirow{2}{*}{$-1,089$} & \multirow{2}{*}{0,279} \\
\hline & Kadın & 42 & 13,45 & 2,19 & & & \\
\hline \multirow{2}{*}{ Katılımcı Yönetim Eksikliği } & Erkek & 50 & 10,46 & 4,63 & \multirow{2}{*}{93} & \multirow{2}{*}{$-0,625$} & \multirow{2}{*}{0,533} \\
\hline & Kadın & 42 & 11,05 & 4,37 & & & \\
\hline
\end{tabular}
${ }^{*} \mathrm{p}<0,05$

Tablo 3'de katılımcıların cinsiyet değişkenine göre mantar yönetim algıları alt boyutları açısından istatiksel analizlerine yer verilmiştir. Elde edilen sonuçlara göre alt boyutlara göre anlamlı bir farkllilı tespit edilememiştir ( $\mathrm{p}>, 05)$.

Tablo 4. İdari Görev Değişkeni Üzerinden Alt Boyutların Karşılaştırıldığı T-Testi

\begin{tabular}{|c|c|c|c|c|c|c|c|}
\hline Ölçek ve Alt Boyutları & Grup & $\mathbf{N}$ & $\mathbf{x}$ & Ss & sd & $\mathbf{T}$ & $\mathbf{P}$ \\
\hline \multirow{2}{*}{ Yetersiz Bilgi Paylaşımı } & İdari Görevi Olan & 32 & 19,0938 & 3,54109 & & \multirow{2}{*}{, 470 } & \multirow{2}{*}{ 630 } \\
\hline & İdari Görevi olmayan & 60 & 18,7167 & 3,72391 & & & \\
\hline \multirow{2}{*}{ Güç Kayb1 Endişesi } & İdari Görevi Olan & 32 & 14,5000 & 3,16228 & & \multirow{2}{*}{,287 } & \multirow{2}{*}{ 485 } \\
\hline & İdari Görevi olmavan & 60 & 14,3167 & 2,78307 & & & \\
\hline \multirow{2}{*}{ Yetersiz İletişim } & İdari Görevi Olan & 32 & 12,5625 & 2,01506 & & \multirow[b]{2}{*}{$-2,050$} & \multirow{2}{*}{813} \\
\hline & İdari Görevi olmayan & 60 & 13,5167 & 2,18230 & & & \\
\hline \multirow[t]{2}{*}{ Katılımcı Yönetim Eksikliği } & İdari Görevi Olan & 32 & 10,4063 & 4,54270 & & \multirow{2}{*}{,- 500} & \multirow{2}{*}{,786 } \\
\hline & İdari Görevi olmayan & 60 & 10,9000 & 4,50122 & & & \\
\hline
\end{tabular}
${ }^{*} \mathrm{p}<0,05$

Tablo 4'de katılımcıların idari görev değişkenine göre mantar yönetim algıları alt boyutları açısından istatiksel analizlerine yer verilmiştir. Elde edilen sonuçlara göre alt boyutlara göre anlamlı bir farkllık tespit edilememiştir ( $\mathrm{p}>, 05)$.

Tablo 5. Yaş Değişkeni Üzerinden Alt Boyutların Karşılaşturıldığı ANOVA Testi

\begin{tabular}{|c|c|c|c|c|c|c|c|c|c|}
\hline Değişken & Bölüm & $\mathbf{N}$ & $\mathbf{x}$ & $\begin{array}{l}\text { Varyansın } \\
\text { Kaynağ1 }\end{array}$ & $\begin{array}{l}\text { Kareler } \\
\text { Toplamı }\end{array}$ & sd & $\begin{array}{l}\text { Kareler } \\
\text { Ortalamas1 }\end{array}$ & $\mathbf{F}$ & $\mathbf{P}$ \\
\hline \multirow{5}{*}{$\begin{array}{l}\text { Yetersiz } \\
\text { Bilgi } \\
\text { Paylaşımı }\end{array}$} & 24-29 Yaş & 15 & 18,47 & Gruplar Aras1 & 76,427 & 4 & 19,107 & \multirow{5}{*}{1,67} & \multirow{5}{*}{0,219} \\
\hline & 30-35 Yaş & 34 & 18,91 & Gruplar İçi & 1133,443 & 87 & 13,028 & & \\
\hline & 36-41 Yaş & 13 & 20,77 & Toplam & 1209,87 & 91 & & & \\
\hline & 42-47 Yaş & 6 & 19,33 & & & & & & \\
\hline & 48 Yaş ve Üzeri & 24 & 17,83 & & & & & & \\
\hline \multirow{5}{*}{$\begin{array}{l}\text { Güç Kaybi } \\
\text { Endişesi }\end{array}$} & 24-29 Yaş & 15 & 13,47 & Gruplar Aras1 & 18,972 & 4 & 4,743 & \multirow{5}{*}{0,551} & \multirow{5}{*}{0,699} \\
\hline & 30-35 Yaş & 34 & 14,35 & Gruplar İçi & 748,713 & 87 & 8,606 & & \\
\hline & 36-41 Yaş & 13 & 14,92 & Toplam & 767,685 & 91 & & & \\
\hline & 42-47 Yaş & 6 & 14,33 & & & & & & \\
\hline & 48 Yaş ve Üzeri & 24 & 14,71 & & & & & & \\
\hline \multirow{4}{*}{$\begin{array}{l}\text { Yetersiz } \\
\text { İletişim }\end{array}$} & 24-29 Yaş & 15 & 13,67 & Gruplar Aras1 & 21,97 & 4 & 5,493 & \multirow{4}{*}{1,183} & \multirow{4}{*}{0,324} \\
\hline & 30-35 Yaş & 34 & 12,88 & Gruplar İçi & 403,888 & 87 & 4,642 & & \\
\hline & 36-41 Yaş & 13 & 14,15 & Toplam & 425,859 & 91 & & & \\
\hline & 42-47 Yaş & 6 & 13,00 & & & & & & \\
\hline
\end{tabular}


Dinç, F., \& Avanoğlu, A. E. (2021). Gençlik ve Spor İl Müdürlüklerinde çalıșanların mantar yönetim algısı üzerine bir çalışma (Niğde ili örneği). Journal of Human Sciences, 18(4), 772-781. doi:10.14687/jhs.v18i4.6249

\begin{tabular}{|c|c|c|c|c|c|c|c|c|c|}
\hline & 48 Yaş ve Üzeri & 24 & 12,83 & & & & & & \\
\hline \multirow{5}{*}{$\begin{array}{l}\text { Katılımc1 } \\
\text { Yönetim } \\
\text { Eksikliği }\end{array}$} & 24-29 Yaş & 15 & 11,40 & Gruplar Aras1 & 42,913 & 4 & 10,728 & \multirow{5}{*}{0,519} & \multirow{5}{*}{0,722} \\
\hline & 30-35 Yaş & 34 & 10,09 & Gruplar İçi & 1797,294 & 87 & 20,659 & & \\
\hline & 36-41 Yaş & 13 & 12,00 & Toplam & 1840,207 & 91 & & & \\
\hline & 42-47 Yaş & 6 & 10,33 & & & & & & \\
\hline & 48 Yaş ve Üzeri & 24 & 10,63 & & & & & & \\
\hline
\end{tabular}

$*_{\mathrm{p}}<0,05$

Tablo 5'de katılımcıların yaş değişkenine göre mantar yönetim algıları alt boyutları açısından istatiksel analizlerine yer verilmiştir. Elde edilen sonuçlara göre alt boyutlara göre anlamlı bir farklılık tespit edilememiştir ( $>$ >,05).

Tablo 6. Görev Süresi Değişkeni Üzerinden Alt Boyutların Karşılaştırıldığı ANOVA Testi

\begin{tabular}{|c|c|c|c|c|c|c|c|c|c|}
\hline Değişken & Bölüm & $\mathbf{N}$ & $\mathbf{x}$ & $\begin{array}{c}\text { Varyansın } \\
\text { Kaynağ1 }\end{array}$ & $\begin{array}{l}\text { Kareler } \\
\text { Toplamı }\end{array}$ & sd & $\begin{array}{c}\text { Kareler } \\
\text { Ortalamas1 }\end{array}$ & $\mathbf{F}$ & $\mathbf{P}$ \\
\hline \multirow{4}{*}{$\begin{array}{l}\text { Yetersiz } \\
\text { Bilgi } \\
\text { Paylaşımı }\end{array}$} & $1-3 \mathrm{y} 1 \mathrm{l}$ & 15 & 19,20 & Gruplar Aras1 & 6,828 & 3 & 2,276 & \multirow{4}{*}{0,166} & \multirow{4}{*}{0,919} \\
\hline & 4-6 y1l & 38 & 18,66 & Gruplar İçi & 1203,042 & 88 & 13,671 & & \\
\hline & $7-9$ y1l & 9 & 19,44 & Toplam & 1209,87 & 91 & & & \\
\hline & 9 ve üzeri yıl & 30 & 18,73 & & & & & & \\
\hline \multirow{4}{*}{$\begin{array}{l}\text { Güç Kaybı } \\
\text { Endişesi }\end{array}$} & $1-3$ y1l & 15 & 13,73 & Gruplar Aras1 & 10,847 & 3 & 3,616 & \multirow{4}{*}{0,42} & \multirow{4}{*}{0,739} \\
\hline & 4-6 y1l & 38 & 14,71 & Gruplar İçi & 756,838 & 88 & 8,6 & & \\
\hline & $7-9 \mathrm{yll}$ & 9 & 14,44 & Toplam & 767,685 & 91 & & & \\
\hline & 9 ve üzeri y1l & 30 & 14,27 & & & & & & \\
\hline \multirow{4}{*}{$\begin{array}{l}\text { Yetersiz } \\
\text { Illetişim }\end{array}$} & $1-3 \mathrm{y} 1 \mathrm{l}$ & 15 & 13,53 & Gruplar Aras1 & 10,364 & 3 & 3,455 & \multirow{4}{*}{0,732} & \multirow{4}{*}{0,536} \\
\hline & $4-6 \mathrm{y} 1 \mathrm{l}$ & 38 & 12,95 & Gruplar İçi & 415,495 & 88 & 4,722 & & \\
\hline & $7-9$ y1l & 9 & 14,00 & Toplam & 425,859 & 91 & & & \\
\hline & 9 ve üzeri yıl & 30 & 13,07 & & & & & & \\
\hline \multirow{4}{*}{$\begin{array}{l}\text { Katılımc1 } \\
\text { Yönetim } \\
\text { Eksikliği }\end{array}$} & $1-3$ y1l & 15 & 9,73 & Gruplar Arası & 31,507 & 3 & 10,502 & \multirow{4}{*}{0,511} & \multirow{4}{*}{0,676} \\
\hline & $4-6 \mathrm{y} 1 \mathrm{l}$ & 38 & 11,32 & Gruplar İçi & 1808,699 & 88 & 20,553 & & \\
\hline & $7-9$ y1l & 9 & 10,11 & Toplam & 1840,207 & 91 & & & \\
\hline & 9 ve üzeri yıl & 30 & 10,67 & & & & & & \\
\hline
\end{tabular}

Tablo 6'de katıllmcıların görev süresi değişkenine göre mantar yönetim algıları alt boyutlanı açısından istatiksel analizlerine yer verilmiştir. Elde edilen sonuçlara göre alt boyutlara göre anlamlı bir farkllık tespit edilememiştir ( $\mathrm{p}>, 05)$.

\section{Tartışma}

Araştırmada, Niğde Gençlik ve Spor İl Müdürlüğü ve bağlı ilçe müdürlüklerinde çalışan personelin mantar yönetim tarzına maruz kalıp kalmama durumlarının belirlenmesi için veri setinden elde edilen bulgulara yer verilmiştir.

Çalışmadan elde edilen bulgulara göre görev süresi, yaş, cinsiyet ve idari görev değişkenlerinde anlamlı farklıklar tespit edilmemiştir. Ancak personelin orta düzeyde mantar yönetime maruz kaldıkları tespit edilmiştir. Benzer bir şekilde, Osmanoğlu ve Üzüm (2020) tarafından yapılan çalışmada spor örgütlerinde çalışanların mantar yönetim algısının orta düzeyde olduğunu belirlemiştir. Ancak aynı çalışmada, çalışmamızdan farklı olarak kadınların erkeklere göre daha fazla mantar yönetime maruz kaldığ 1 belirlemiş ve çalışma yılı arttıkça mesleki doyumun artmas1 nedeniyle mantar yönetim algısının arttı̆̆ını ileri sürmüşlerdir. Kılıç (2015), sağlık sektöründe çalışanların, büyük bir kısmına yöneticileri tarafindan mantar yönetim uyguladığını belirlemiştir. Tekin ve Birincioğlu (2017), devlet üniversitelerinde çalışan araştırma görevlilerine bilgi asimetrisi uygulandığını ve orta düzeyde olsa yönetici seviyesindeki akademisyenler tarafından mantar yönetim tarzına maruz kaldıklarını tespit etmişledir. Kılıç ve Olgun (2017), sağlık çalışanlarının orta düzeyde mantar yönetime maruz kaldığını ve bu yönetim şeklinin şeffaf, anlaşlır ve demokratik olmadığını belirtmekle birlikte işletmedeki kaosu ya da krizi önlemek adına 
Dinç, F., \& Avanoğlu, A. E. (2021). Gençlik ve Spor İl Müdürlüklerinde çalıșanların mantar yönetim algısı üzerine bir çalışma (Niğde ili örneği). Journal of Human Sciences, 18(4), 772-781. doi:10.14687/jhs.v18i4.6249

uygulanabileceğini belirtmektedirler. Benzer bir şekilde, Smart (2012)'a göre titanik gemisinin buzdağına çarpmak üzere olduğunu sayılı kişinin bilmesinin panik ortamını engellemek olmasıdır. Neill ve Laplante (2005), sınırlı bilgi ve sorumluluğa sahip olan çalışanlarda iş strenin daha az olmasını belirtmesi mantar yönetimin olumlu yönlerindendir. Ayrıca Kahya ve Ceylan (2019), çalışmasında özel sektörde faaliyet gösteren işletmelerde mantar yönetim uygulandığını ve çalışanların performanslarının düştügüünü belirlemiştir. Çetin (2021) mantar yönetim algısına sahip personelin iş tatminsizliği yaşadığ1 ve işe yabancılaşmanın aracıllğı ile mantar yönetim algisı olan çalışanın iş tatminsizliği yaşadığını belirlemiştir. Çetinkaya ve Altıntaş (2021) göre mantar yönetimin erdemli raporlamayı etkilediği işletme içerisinde negatif yönde, işletme dışında ise pozitif yönde anlamlı bir ilişki tespit etmişlerdir. Tekin ve Birincioğlu (2017), nitel araştırma yöntemleri ile yapılan araştırmalarında detaylı görüşmeler sonrasında üniversitelerde çalışan araştırma görevlilerin mantar yönetim tarzına maruz kaldıklarını tespit etmişledir. Öztürk ve Aras (2021) ise mantar yönetim tarzının benimseyen işletmelerde çalışanların dedikodu tarzı bigileri birbirleriyle paylaştıkları ve birazda olsa mantar yönetim tarzı ile ortaya çıkan bilgi asimetrisinin önüne geçildiğini belirlemiştir. Bu bilgiler 1şığında çalışanların, kamu ya da özel sektör fark etmeksizin mantar yönetime maruz kaldığ1 söylenebilir Literatür incelemeleri sonucunda mantar yönetimin iş yerinde çalşsanları olumsuz etkilediği, iş tatminlerini bir şekilde etkilediği ve bilgi asimetrisine neden olduğunu belirten çalışmaların yanı sıra iş yerinde krizi engelleme paylaşılmaması gereken bilgilerin olması gibi nedenler ile mantar yönetimin olumlu yönlerini belirten çalışmalar bulunmaktadır.

Sonuç olarak, Niğde Gençlik ve Spor İl Müdürlüğü ve bağlı ilçe müdürlüklerinde çalışanların orta düzeyde mantar yönetime maruz kaldıkları tespit edilmiştir. Kurum içi iletişimde bilgi paylaşımının yeterli düzeyde olduğu söylenebilir. Bu durum örneklem grubunda bulunan yöneticiler ve çalışanların spor örgütü içerisinde görev yapmalarından kaynaklanabilir. Birçok çalışmada spor ile ilgilenen bireylerin sosyal ve iletişim kanalların açık olduğu belirlenmiştir. Bu durum literatürde ve araştırmamızda mantar yönetim algısının yüksek olmamasının sebebi olarak ortaya konulabilir. Buna dayanarak çalışanların kamu personeli olması, kamu birimlerinde görev ve yetkilerin daha net biçimde tanımlanmış olması, bundan kaynaklı olarak da personelin üst birimler tarafından aktarılan bilginin yeterli olduğunu düşündükleri söylenebilir. Bununla birlikte çalışanların idari görevi olan ve olmayanların, yaş, görev süresi ve cinsiyetlerine göre anlamlı farklılıklar tespit edilememiştir. Mantar yönetim ile bu değişkenler arasında anlamlı farklılıkların olmaması yapılan diğer araştırmalar ile benzerlik göstermemektedir. Elde edilen bu sonuca göre kurum içinde yöneticiler ve çalışanların doğrudan ya da dolaylı yollardan sporun içinden gelen ve spor ile ilgilenen bireyler olması sosyal ve iletişim kanalların açık olması nedeniyle mantar yönetim algısının yüksek olmamasının sebebini açıkladığını söyleyebilir.

Dünyada ve ülkemizde spor örgütleri kapsamın mantar yönetim anlayışı ile ilgili çalışma sayısı oldukça kısıtlıdır. Bu hususun göz önünde bulundurulmasıyla spor yönetimi alan yazınına katk1 sağlayacağı düşünülmektedir. Bu araştırmanın sınırlılığı sadece Niğde İl Gençlik ve Spor İl Müdürlügünden verilerin toplanmasıdır. Araştırma ile ilgili daha detaylı sonuçlara ulaşmak için araştırmanın kamu ve özel spor örgütlerini kapsayacak bir şekilde geniş bir örnek grubu ile yapılması önerilmektedir.

\section{Kaynaklar}

Akşit, Z. (2005). Spor ve beslenme. Nobel Yayın Dağtım, 4. Baskı. Ankara.

Altan, S., \& Özpehlivan, M. (2019). Otokratik ve Katılımcı Liderlik Anlayışının Örgütsel Vatandaşlık Davranışı Üzerine Etkisi: Sivil Toplum Kuruluşları Üzerine Bir Araştırma. The Journal Of Social Science, 3(5), 208-229.

Arazi, H. \& Hosseini, R. (2012). A comparison of nutritional knowledge and food habits of collegiate and noncollegiate athletes. SportLogia, 8(2), 100-107.

Asfuroğlu, Y. (2013). Sporcularda sıvı tüketimi vücut bileşimi ve beslenme durumu arasındaki ilişkinin değerlendirilmesi. Beslenme ve diyetetik yüksek lisans programı, İstanbul Bilim Üniversitesi Sağllk Bilimler Enstitüsü, İstanbul. 
Dinç, F., \& Avanoğlu, A. E. (2021). Gençlik ve Spor İl Müdürlüklerinde çalıșanların mantar yönetim algısı üzerine bir çalışma (Niğde ili örneği). Journal of Human Sciences, 18(4), 772-781. doi:10.14687/jhs.v18i4.6249

Baxter, L. (2005). Top Definition mushroom management, www.urbandictionary.com/ author.php?author=Lance+Baxter, Erişim Tarihi 01.06.2021

Baysal A. (2015). Beslenme. Hatiboğlu Yayınevi, 16. Baskı. Ankara.

Birincioğlu, N., \& Tekin, E. (2018). Mantar Yönetim Ölçeği Geliştirilmesi Üzerine Bir Çalışma. Business and Economics Research Journal, 9(1), 169-186.

Çelik, A. ve Şimşek, M.Ş. (2018). Yönetim ve Organizasyon, Konya: Eğitim Yayınevi, (20. Baskı).

Çetin, O. I. (2021). Mantar Yönetim Algısının İş Tatminine Etkisinde Yabancılaşmanın Aracı Rolü. OPUS Uluslararası Toplum Araştırmaları Dergisi, 17(33), 398-424.

Çetinkaya, F. F., \& Altıntaş, M. (2021). Whıstleblowıng (Erdemli Raporlama) ve Mantar Yönetim Arasındaki İlişki. Fırat Üniversitesi Sosyal Bilimler Dergisi, 31(2), 781-793.

Çırak, O. \& Çakıroğlu, F.P. (2019). Sporcu beslenme bilgisi ölçeğinin Türkçe formunun geçerlik ve güvenirlik çalışması. Ankara Sağlık A. A. Yetim, (2019). Yönetim Bilimi: Tarihi Gelişim Süreci ve Alt Dalları," Yönetim ve Spor, Ankara: Gazi Kitabevi, s.3-32.

Geckoboard \& Censuswide (2015). Mushroom management: Leaves employees heading for the door. www.geckomoard.com. Erişim Tarihi 01.06.2021

Gunn, B. (1995). The paradigm shift in university management. International Journal of Educational Management. 09(01), 28-40

Herman, Roger E. (1997). The Process of Excelling: The Practical How-to Guide for Managers and Supervisors Greensboro, NC: Oakhill Press Google Books, Pg. 66:

Kahya, V., ve Ceylan, E. (2019). İş performansını artırmada yeni bir yaklaşım: Mantar yönetim. Uluslararası Sosyal ve Beşeri Bilimler Araştırma Dergisi, 4(45), 3773-3781.

Kılıç, T. (2015). Mushroom Management Theory Sample of Health Sector, Academy Of Strategıc Management Journal, Volume 14, Special Issue, s,85-91

Kılıç, T., \& Olgun, H. (2017). Mantar Yönetim Yaklaşımı. Örgütsel Davranış Araştırmaları Dergisi, 2(2), 106113.

Korkut, G., Kürşat, O., \& Tetik, A. (2015). Yeni kamu yönetimi anlayışı ile değişen kamu hizmeti ve Türkiye İş Kurumu. İş ve Hayat, 1(2), 107-135.

Mar, A.(2011) "Mushroom Management, http://management.simplicable.com/ management/new/ mushroom-management. Erişim Tarihi: 01.06.2021

Neill, C. J., \& Laplante, P. A. (2005). Antipatterns: identification, refactoring, and management. CRC Press.

Osmanoğlu, H., \& Üzüm H. (2021). Gençlik ve Spor İl Müdürlükleri Çalışanlarının Mantar Yönetimi Alg1 Düzeyleri Üzerine Bir Araştırma. Spor Bilimleri Araştırmaları Dergisi, 5(2), 293-302.

Öztürk, İ., Aras M. (2021). Mantar Yönetim Tarzi ve Örgütsel Dedikodunun Bilgi Paylaşimina Etkisi. Doğuş Üniversitesi Dergisi, 22(2), 121-134.

Smart, J.M. (2012). Saving the Titanic- Crowdsourcing to Find Hard Solutions, and Unlearning to Implement Them. https://eversmarterworld.wordpress.com/tag/ mushroom-management/, Erişim tarihi 01.06.2021

Smith, G. P. (2002). Mushroom Management-Don't keep your workforce in the dark. Manager Wise.

Tekin, E., \& Birincioğlu, N. (2017). Bilgi Çağının Odak Noktası Üniversitelerde Mantar Yönetimi. International Journal of Academic Value Studies (Javstudies), 3(14), 22-29

Turan, M. \& Güler, M. (2018) Yerel Yönetimler. K. Görmez\& H. Yayl. Yerel yönetimlere ilişkin temel kavramlar, (5-32): Ankara.

\section{Extended English Summary}

Today, businesses have adopted new management approaches to adapt to changing and developing market conditions in order to refine their efficiency. In order to keep up with the rapidly increasing and diversifying market conditions, the necessity of applying workforce management in an effective and coordinated manner emerges for businesses or institutions (Korkut et al. 2015). In recent years, the mushroom management model as a new management approach has appeared in the relevant literature. However, the literature on this subject is limited. The mushroom management metaphor is giving limited information to employees about their institutions and duties (Herman, 1997,66). The concept of mushroom management has emerged as a metaphor inspired by mushroom cultivation. In mushroom cultivation, the mushrooms are left in the dark, and fertilizer and water are 
Dinç, F., \& Avanoğlu, A. E. (2021). Gençlik ve Spor İl Müdürlüklerinde çalıșanların mantar yönetim algısı üzerine bir çalışma (Niğde ili örneği). Journal of Human Sciences, 18(4), 772-781. doi:10.14687/jhs.v18i4.6249

given to them as needed. In this understanding of metaphor, managers expect maximum performance from employees, leaving them in the dark, as in mushroom cultivation. Managers who expect high benefits leave employees in the dark by only giving them the information and resources they need (Birincioğlu and Tekin, 2018: 170, Kılıç 2015). Managers with this attitude do not share their knowledge and power with their employees. However, they get the jobs done by giving their subordinates as much information as they think they need. (Mar, 2011). In terms of the mushroom management approach, employees are not required to access more information than necessary, express themselves and participate in the decisions taken. In this management approach, leaders tend to make decisions on their own. Therefore, a democratic organization cannot be mentioned (Mar. 2011, Kıliç and Olgun 2017). From this point of view, it can be said that managers who exhibit autocratic leadership characteristics exhibit an attitude that coincides with the mushroom management approach. Autocratic leaders hold authority, plans, and decisions, and do not give their subordinates a say (Altan and Özpehlivan 2019).

The mushroom management approach can have positive and negative results in sports organizations as in many organizations. In line with this information, this study aimed to examine the mushroom management perception of the employees working in the Niğde Provincial Directorate of Youth and Sports. In the light of the findings to be obtained, the results are thought to be important in terms of contributing to the field. Moreover, suggestions can be made from an institutional point of view. This study is a descriptive and quantitative study and is in the descriptive survey model. Does the perception of mushroom management differ according to age, gender, tenure, education level, and administrative duty? Answers were sought to these questions.

90 people out of a total of 185 personnel working in $4 \mathrm{a}$ and $4 \mathrm{~b}$ status for Niğde Youth and Sports Provincial and District Directorates were reached due to the pandemic. The study was examined ethically by the ethics committee of Niğde Ömer Halisdemir University and it was unanimously decided that it was ethically appropriate at the meeting dated 01/04/2020 and numbered 03. The informed consent form was obtained from the participants.

Personal information form and the "Mushroom Management Scale" developed by Birioğlu and Tekin (2018) were used as data collection tools in the research. A 5-point Likert-type rating was used to express Mushroom Management related to the items in the scale. The scale consists of 19 items and a four-factor structure. These factors are Inadequate Information Sharing $(1,2,3,4,5,6)$, Anxiety of Power Loss (7, 8, 9, 10, 11), Lack of Communication (12, 13, 14, 15), and Lack of Participation Management (16, 17, 18, 19). Cronbach's alpha coefficient was calculated for the internal consistency reliability of the scale, and the internal consistency coefficient of the 19-item scale was calculated as 0.90 . The internal consistency coefficients for the sub-factors of the scale were 0.89 for insufficient information sharing; 0.87 for power loss concern; 0.81 for lack of communication and 0.83 for lack of professional management (Birincioğlu \& Tekin, 2018). The data were obtained with face-to-face survey type, by hand-delivery of the questionnaire. Descriptive statistics were used in the analysis of the data and whether the data showed a normal distribution or not was examined with the Kolmogorov Smirnov test. T-test from parametric tests was used for pairwise comparisons, and ANOVA tests were used for more than two comparisons.

According to the findings obtained from the study, no significant differences were found in terms of tenure, age, gender, and administrative duty variables. However, it was determined that the employees were exposed to moderate Mushroom Management. Similarly, in the study conducted by Osmanoğlu and Üzüm (2020), it was determined that the mushroom management perception of employees in sports organizations is at a moderate level. However, in the same study, they determined that, unlike our study, women were more exposed to mushroom management than men, and they argued that as the working year increases, the perception of mushroom management increases due to the rise in occupational satisfaction. Kılıç (2015), in his study using qualitative research method, determined that most of the healthcare professionals apply mushroom management by their managers. Tekin and Birioğlu (2017) found that research assistants working in state universities are exposed to information asymmetry and that they are exposed to a mushroom management style by 

çalışma (Niğde ili örneği). Journal of Human Sciences, 18(4), 772-781. doi:10.14687/jhs.v18i4.6249

academics at the middle level. The fact that these studies in the literature were carried out in a public institution, as in our research, can be stated as the reason for the medium level of mushroom management perception.

As a result, it has been determined that employees in Niğde Provincial Directorate of Youth and Sports and its affiliated district directorates are exposed to moderate Mushroom Management. It can be said that information sharing is at a sufficient level in internal communication. This may be due to the fact that the managers and employees in the sample group work in the sports organization. In many studies, it has been determined that the social and communication channels of individuals interested in sports are open. This situation can be put forward as the reason why the perception of mushroom management is not high in the literature and in our research. Based on this, it can be said that because the employees are public personnel, the duties and authorities in the public units are more clearly defined, and as a result, the personnel thinks that the information conveyed by the upper units is sufficient.

The limitation of this research is the collection of data only from Niğde Provincial Directorate of Youth and Sports. In order to reach more detailed results about the research, it is recommended that the research be conducted with a large sample group, including public and private sports organizations. 